\title{
Assessing Students' Satisfaction with Library Service Delivery at University of Health and Allied Sciences, Ho
}

ELIAS KORMLA TSEH ( $\square$ etseh@uhas.edu.gh ) UNIVERSITY OF HEALTH AND ALLIED SCIENCES https://orcid.org/0000-0001-7359-7854

\section{Research Article}

Keywords: Students' satisfaction, Service delivery, UHAS, Ho

Posted Date: September 2nd, 2021

DOl: https://doi.org/10.21203/rs.3.rs-870941/v1

License: (c) (i) This work is licensed under a Creative Commons Attribution 4.0 International License.

Read Full License 


\section{Abstract}

The purpose of the study was to investigate students' satisfaction with service delivery in the University of Health and Allied Sciences (UHAS), Ho. Research survey of students was adopted. Sample size of 151 made up of students from selected departments at UHAS participated in the study. Data from the questionnaire was analyzed using frequency counts and percentages by using Statistical Package for Social Sciences SPSS (version 22). Five areas of service delivery namely: library, ICT, health, transportation, and hostel services were considered in the study. A number of significant findings were made from the study. The results revealed that majority of the students indicated dissatisfaction with health, transport as well as Information and communication Technology services (ICT), while others showed little level of satisfaction with library and hostel services. Again, it was revealed that students' satisfaction with service delivery in terms of library and hostel services significantly differ by other services, while, they show much significant difference in their satisfaction with transport, health and ICT services. It was recommended that the university management should enhance students' satisfaction by ensuring all services that contribute to academic and social life of students in UHAS are delivered to acceptable and satisfactory standards. Again, it was recommended that the government should provide the necessary financial support or resources to management to meet acceptable standards in service delivery and surveys to assess students' satisfaction with service delivery should be on regular basis by management to ascertain the satisfaction needs of students.

\section{Introduction}

\section{Background to the Study}

Over the past decades, the Ghanaian tertiary institution has experienced unprecedented expansion. Institutions that few years ago was somehow seen as an oligopoly market, with four public universities namely University of Ghana, Kwame Nkrumah University of Science and Technology, University of Cape Coast and University of Education Winneba of which University of Health and Allied Science is no exception and few regional polytechnics; can now boast of ten (10) public Universities and one hundred and thirty four tertiary (134) institutions (National Accreditation Board (NAB) 2016: Report). The rapid surge in the development of tertiary institutions in Ghana has been made largely possible due to the collaborative efforts of the government and the involvement of the private sector with some non governmental organizations in the development of tertiary education in the country Dei Ofori-Attah (2007). The growth in e-commerce is also a contributing factor in the ease of accessing tertiary education in Ghana. Many Ghanaians are pursing programmes with internationally acclaimed universities and colleges at the comfort of their homes by distance, a situation which was impossible at first to attain. The market will continue to offer many opportunities for private players and foreign institutions to enter; with the internet playing a leading role in this aspect. The resultant effect of this enormous expansion is students' demand for quality service of which management of these institutions cannot consider as secondary. Reduction in cost of travelling as well as improvements in communications such as television networks and the internet has also contributed to a convergence of preferences in a number of courses 
and how they are delivered. The revolution and expansion in the sector makes traditional teaching and learning techniques and conditions to no longer follow a fixed model or necessarily graduating students a pattern; as a result, innovation and customer service management reform had superseded not only training of students but all other culture of our education and has taken more significant roles in our educational sector. Thus, students' service management has become the foundation and core of the new education economy of the 21 st Century. It is driven by students ever changing demands and expectations have been pivoted around to today's competition strategies of educational managers.

Individuals are very much more than a merely productive factor in management plans. They are consumers of goods and services and thus, they vitally influence demand. Individual learners can be helped to satisfy their own needs and utilize their potentials and at the same time contribute to the aims of an enterprise. Institutions of high learning should thus have an understanding of the roles assumed by learners, the individuality and the personalities of learners. It is equally important to acknowledge that individuals are unique. They have different needs, ambitions, attitudes and desires for responsibility, different levels of knowledge and skills and different potentials. Achieving results is important, but the means of it must never violate the dignity of learners. This concept implies that learners must be treated with respect, no matter their positions.

\section{The Structure of the University}

The University of Health and Allied Sciences, Ho (UHAS) was established by an Act of Parliament (Act 828 in December, 2011) and envisioned to become a pre-eminent research and practically oriented health educational institution dedicated to community service. The main campus including the central administration is in Ho. A second campus is located in Hohoe.

The University started operations in September, 2012 with 154 students. Students' population currently stands at 3,752 (3,727 undergraduates and 25 postgraduates) while the staff strength is 611 . Staff to student ratio in UHAS is 17:1, which is currently the best among all state universities in Ghana.

The University currently runs eighteen (18) undergraduate programmes in six (6) schools and one (1) institute, namely; School of Allied Health Sciences (SAHS), School of Basic and Biomedical Sciences (SBBS), School of Medicine (SOM), School of Nursing and Midwifery (SONAM), School of Public Health (SPH), School of Pharmacy (SOP) and Institute of Health Research (IHR). Others yet to be established are School of Sports and Exercise Medicine, School of Dentistry, Institute of Medical Education and Institute of Traditional and Alternate Medicine.

\section{Statement of the Problem}

With the current drive for University education and the increasing number in enrolments, the issue of service delivery becomes paramount. Universities offer diverse services to students to enable them succeed in their academic endeavors. Students as the prime beneficiaries of University education, require quality service in order to carry out their studies. Inefficient service delivery can affect students in their 
academic performance. Of recent, there have been complaints about some of the services rendered to students in the Universities as unsatisfactory of which UHAS is no exception.

The students complain about poor transport services, the appalling hostel conditions, and poor library services and so on. Students' dissatisfaction with service delivery often manifests in the form of reactions, either through peaceful protest or outright riot, which are sometimes witnessed in our Universities. Although no cases of danger or outright riot has ever happened which may trigger into demonstrations or protest against the University management, majority of the students shared a lot of their aggrieved emotions about hostel accommodation and transport issues on campus of which they are totally not satisfied with and need to be addressed on time. Students' reactions are sometimes violent and results in the destruction of the institutions properties when they are not satisfied with their pressing needs. In most recent times, there was an incidence whereby a staff at the library asked a student to leave the library in order to close for the day and the student feel reluctant to leave since the student was not satisfied with his needs for using the library; he sent a personal email to the University librarian reporting the staff. This happens because the student was dissatisfied with the services of the library in terms of time duration. Similarly, students complain about intra- transport charges by paying additional fees to commercial buses arranged by the transport unit to convey students from some designated standpoints to the main campus for their lectures. This is a kind of service that the University has put in place to address transport issues on campus for students but it has turned to be otherwise. Also, hostel facilities that should seek to provide students with accommodation is inefficient and hence dissatisfied students. Once they are not satisfied with the service delivery by the University services, it would one way or the other result in unprecedented peace demonstration or outright riot among students and management.

From the foregoing issues, the pertinent questions underlying this study are:

- To what extent are students satisfied with service delivery in terms of transport, library, health, hostel accommodation and ICT services in the University of Health and Allied Sciences, Ho?

- Does students' satisfaction with service delivery vary with institutional type?

The present study intends to provide answers to these questions.

\section{Purpose of the Study}

The purpose of this study is to get feedback from students on their satisfaction levels with five areas of services that are delivered to them at the University of Health and Allied Sciences, Ho. Specifically, the study sought to determine the extent to which University students' are satisfied with service delivery with library, health, transportation, hostel and ICT at the University of Health and Allied Sciences, Ho. 
1. To identify what kind of quality service delivery students' would like to receive at UHAS.

2. To investigate students' perception or views on service delivery at UHAS.

3. To determine the satisfaction level of students' on various service delivery at UHAS.

4. To find out whether students' are prepared to pay for quality service delivery at UHAS.

5. To find out the relationship between students' satisfaction at UHAS and its implication on students' decision making and loyalty to management.

\section{Research Question}

The following research questions were formulated to guide the survey conducted at UHAS;

1. To what extent are students' satisfied with library service delivery at University of Health and Allied Sciences (UHAS), Ho?

2. To what extent are students' satisfied with health service delivery at UHAS, Ho?

3. To what extent are students' satisfied with transport service delivery at UHAS, Ho?

4. To what extent are students' satisfied with hostel service delivery at UHAS, Ho?

5. To what extent are students' satisfied with ICT service delivery at UHAS, Ho?

\section{Limitation of the study}

The scope of study is narrowed to a single public University in Ghana that is UHAS. Albeit the data is a representative, it limits itself to the University students' on one campus from all the six schools and dealt with 151 participants. Extending the selection of participants to other campus or increasing the sample size will have altered the results of the study.

\section{Literature Review}

In times of tough tertiary education competition where many institutions offer similar products in terms of fees, content of modules and quality; students' service differential can provide organizations with distinct competitive advantage. Since severe competition results in little variation of facilities, quality of students' service has been regarded as one of the main factors, whether or not the school operates successfully. The irony is that many more tertiary institutions are not taking this icon of business seriously even though they are the same players who teach their students the concept of customer service. Also, for those that had already established students services and business development departments are also reluctant to properly invest into it, leaving just the structure and printed "business 
and service department" on walls to win business and attract more students for them ironically (Mast \& Zaltman, 2005).

The frontline activities of Universities remain teaching and learning in order to produce high level manpower necessary for national development. The beneficiaries of University education are the students who attend Universities to obtain degrees that will guarantee employment opportunities for them. Universities, apart from academic services, offer diverse services to students to enable them succeed in their academic pursuits. Such services include library, health, transport, hostel, information and communication technology (ICT), and so on.

These services are part of Universities wide programmes aimed at ensuring sound learning by students. According to Ayodele and Falokun (2003), has observed that learning environment should be enriched, so as to stimulate students' wholesome development, since a comfortable student will be motivated to learn. Thus, it is imperative that whatever services offered to students should be of an acceptable standard. Students' satisfaction with service delivery in an institution is very paramount since the extent to which services satisfy the needs of users will determine how effective and efficient an institution is Gyamfi, Agyeman, Otoo, and Sciences (2012), consider students' satisfaction to involve the comparison of standards by receivers whether they are in the form of expectations, desires and works ideal or equitable performance. Also, M. N. Abbasi, Malik, Chaudhry, and Imdadullah (2011) defines satisfaction as what students expect from their educational institutions, involving everything that makes them eligible to become productive and successful persons in their practical lives.

Students' satisfaction with service delivery is an indication that an institution is able to meet their expectations and needs. However, students are dissatisfied when the services are below their expectations, and if the gap between expected service deliveries is high, they tend to communicate the negative aspects given, since they expect to see value for their time and money(Katamei, Kiprop, \& Research, 2015). Students' dissatisfaction can result in noticeable adverse or negative reactions. This they sometimes show through demonstration, protest or outright riot. Several incidences occurred in some notable public Universities in Ghana, such as University of Ghana, in 2018; the students went on demonstration due to increase in academic user tuition fees. A similar situation also occurred in some other Universities in Ghana, when the students protested against increase in academic user fees and SRC dues as well as inadequate hostels to accommodate freshmen. The two cases cited above indicate that students are not passive receivers of services rendered to them. As observed by Ekpoh (2018) any unsatisfied service rendered to students will ultimately affect their behavior.

Teya (2011) has pointed out that in the competitive environment, delivery of outstanding quality service so as to ensure customer satisfaction should be seen as a major impetus in nurturing an organization's long-term survival. Also, Abdullahi (2009) noted that the main objective of any University is to maximize students' satisfaction and minimize dissatisfaction and in turn improve the institutions performance. Ekpoh (2018) assert that the measurement of satisfaction in Universities students' services is regarded as the basic indicator of programme effectiveness and success. Students' satisfaction or 
dissatisfaction is an important issue to be considered and addressed in all service oriented organizations. The services provided to students can make their experiences pleasant and acquisition of necessary skills and abilities possible.

A. Abbasi, Altmann, and Hossain (2011) argued that students' satisfactions with offerings at Universities are important for them to acquire more skills and abilities needed for their individual success, as well as, that of the economy. Students' satisfaction with educational experience is an important tool to assess the institutional effectiveness and quality of teaching and learning services. Equally, customers' feedback is important.

Getting feedback (comments and complaints) from students is an important way of providing improvement in the services provided by the institution. The views, opinions and perceptions of serviceusers should be sought, if the University wants to improve its services. In order to identify areas of weaknesses and improve on them. Also, it is noted that students' feedback restores confidence in the ability of the University to meet their needs and also facilitates stronger students' retention. In the same manner, Hussain and Bhamani (2012) noted that, incorporating students' feedback can influence positively the service quality of any institution and also support the University in various ways. For instance, it can allow the institution to benchmark and provide indicators that will contribute to the reputation of the University in the market place. However, the views and feedback of students with regard to service delivery is lacking in many educational institutions, hence the present study in assessing students' satisfaction at the University of Health and Allied Sciences, Ho with service delivery in library, Information and Communication Technology, health, transport and hostel will go a long way to put the University ahead of others public institutions in line with quality service delivery.

\section{The Method}

Questionnaires were distributed to 151 students from six schools namely, School of Nursing and Midwifery (SONAM), School Basic and Biomedical Sciences (SBBS), School of Allied Health Sciences (SAHS), School of Pharmacy (SOP), School Medicine (SOM) and School Public Health (SPH) of the University of Health and Allied Sciences, Ho, to collect data. Close-ended questionnaire was used to collect the required data from the respondents as it was convenient for both the respondents as well as the researcher. Questionnaires were distributed to respondents directly by the researcher and the researcher waited for their responses. Collected data was processed using Statistical Package for Social Sciences (SPSS) version 22 and later presented for analyses based on frequencies and percentages for easy interpretations.

\section{Discussion Of Findings}

\section{Table 1.1}

Response to data based on Gender, Age and Levels. 


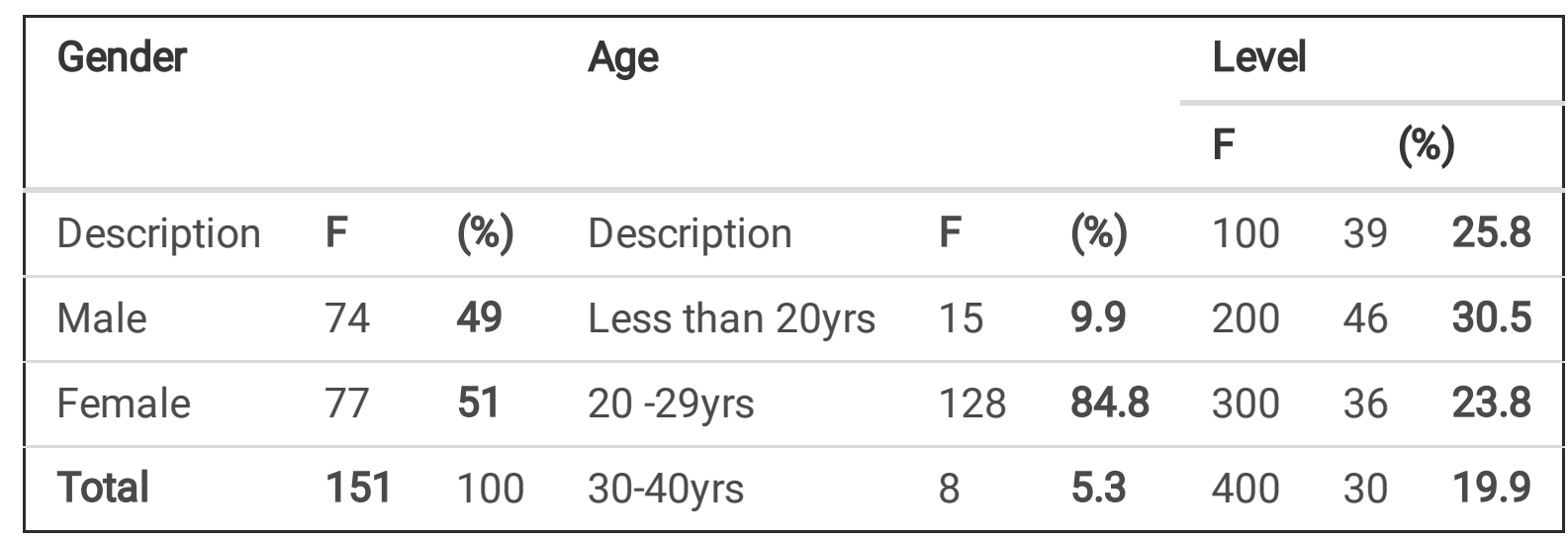

Source: Field work (2020)

Table 1.1 shows gender, age and levels of students for the study. Based on gender, 74 (49\%) were males whereas; 77 (51\%) were females.

For age, 15 (9.9\%) were less than 20 years, 128 (84.8\%) aged between (20-29) years and 8 (5.3\%) aged between (30-40) years. Also, based on the level of students, level 100 were $39(25.8 \%)$, level 200 were 46 (30.5\%), level 300 were $36(23.8 \%)$ and level 400 were 30 (19.9\%). From the table, it can be observed from the distribution that majority of the students fall between the ages of (20-29) years who should be provided with needed support in order to excel academically. It was revealed that students within these categories must be provided with the needed services to enhance their knowledge in some dimensions, especially in the dimension of studies engagement, vigor and dedication towards studies. A close look at the distribution of students by their levels means that adequate services are needed in terms of service delivery in order to foster good academic work.

\section{Table 1.2}

Level of satisfaction with library service delivery at UHAS by students

\begin{tabular}{|lllllll|}
\hline Statement & $\mathbf{1}$ & $\mathbf{\%}$ & $\mathbf{2}$ & $\%$ & $\mathbf{3}$ & $\%$ \\
& $\mathbf{( F )}$ & & $\mathbf{( F )}$ & & (F) & \\
\hline Reading environment & 39 & 25.8 & 91 & 60.3 & 21 & 13.9 \\
\hline Availability of current materials(books, journals, articles) & 21 & 13.9 & 92 & 60.9 & 38 & 25.2 \\
\hline Adequacy of sitting place(s) & 28 & 18.5 & 53 & 35.1 & 70 & 46.4 \\
\hline Knowledge and competence of library staff & 19 & 12.6 & 98 & 64.9 & 34 & 22.5 \\
\hline Book lending policies & 24 & 15.9 & 95 & 62.9 & 32 & 21.2 \\
\hline Opening hours of the Library & 24 & 15.9 & 64 & 42.4 & 63 & 41.7 \\
\hline Reprographic services (printing, photocopies) & 18 & 11.9 & 59 & 39.1 & 74 & 49.0 \\
\hline
\end{tabular}

Source: Field work (2020) 
Research question one. To what extent are students' satisfied with library service delivery at UHAS?

The results presented in Table 1.2 shows the responses based on $1=$ Very Satisfied; $2=$ Satisfied; $3=$ Dissatisfied

Table 1.2 indicates students' response on their levels of satisfaction with library service delivery in the University of Health and Allied Sciences, Ho. The findings per the statements reveal that, students were satisfied with the reading environment of the library (60.3\%), availability of current materials $(60.9 \%)$, knowledge and competence of library staff (64.9\%) and book lending policies (62.9). The opening hours of the library obtained a moderate satisfaction response of (42.4\%), hence needs greater improvement. Some students indicate dissatisfaction with adequacy of sitting places (46.4\%) and reprographic services (such as; printing and photocopies) (49.0\%). The analysis shows that majority of the students were satisfied with library services, whereas few were dissatisfied based on the opening hours and other auxiliary services provided by the library. From the analysis, it could be inferred that students were satisfied with library services but not very satisfied. Nnadozie (2006) indicated that basic facilities and tools needed to deliver quality library services were most of the time either not available, inadequate in quantity or out rightly not in existence, hence explains why users were not satisfied with library services. Also, Mu (2007), said that libraries need to market their services and resources proactively to students who are not familiar with the services and resources in a Western academic library. Reference librarians need to consider these learners' characteristics, language proficiency, learning styles and their subjects of interests so that the teaching methodology and examples used are effective with these students. Hence, there is the need to improve on the areas identified in order to address the satisfaction needs of students at UHAS. Moreover, Ekpoh (2018) asserted that one of the critical challenges of meeting 21 st century demands of Ghanaian universities is the ever increasing population growth, inadequate library resources and facilities. It shows that once the population is growing, there should be adequate provision of resources to meet the demands of students in terms of service delivery in the library by expanding infrastructure to cater for the growing number of students at UHAS, Ho.

\section{Table 1.3}

Level of satisfaction with ICT service delivery at UHAS by students 


\begin{tabular}{|lllllll|}
\hline Statement & $\mathbf{1}$ & $\mathbf{\%}$ & $\mathbf{2}$ & $\mathbf{\%}$ & $\mathbf{3}$ & $\%$ \\
& $\mathbf{( F )}$ & & $\mathbf{( F )}$ & & (F) & \\
\hline Availability of ICT facilities (computers, servers, etc.) & 13 & 8.6 & 77 & 51.0 & 61 & 40.4 \\
\hline Availability of Cyber Café on Campus & 9 & 6.0 & 51 & 33.7 & 91 & 60.3 \\
\hline Cost of ICT services on campus & 15 & 9.9 & 82 & 54.3 & 54 & 35.8 \\
\hline Power supply & 26 & 17.2 & 101 & 66.9 & 24 & 15.9 \\
\hline Access to Internet on campus & 20 & 13.2 & 54 & 35.8 & 77 & 51.0 \\
\hline Internet speed or Internet coverage & 12 & 7.9 & 41 & 27.2 & 98 & 64.9 \\
\hline Attitude of ICT staff & 17 & 11.3 & 92 & 60.9 & 42 & 27.8 \\
\hline
\end{tabular}

Source: Field work (2020)

Research question two. To what extent are students' satisfied with ICT service delivery at UHAS? The results presented in Table 1.3 shows the response based on $1=$ Very Satisfied; 2 = Satisfied; 3 = Dissatisfied In line with Table 1.3, it shows the extent of students' satisfaction with ICT service delivery at UHAS, Ho. The results further indicate that the students were dissatisfied with availability of cyber café on campus $(60.3 \%)$, access to internet on campus (51.0\%), internet speed or internet coverage (64.9\%). In terms of availability of ICT facilities (such as; computers, servers) (51.0\%), cost of ICT services on campus, (54.3\%), power supply (66.9\%) and attitude of ICT staff (60.9\%) were satisfied. It can be observed; therefore, that students were dissatisfied with three of the statements and were marginally satisfied with only four signally that the satisfaction with the ICT service delivery was not adequate hence needs to be addressed by management of the University of Health and Allied Sciences. The key components of the ICT services that need to be available at all times to meet the needs of the students were rather not available therefore caused the students not to be satisfied but rather dissatisfied. It can therefore be inferred that students were not satisfied with ICT service delivery at UHAS, Ho. Although other items were somehow good, access to internet on campus was poor due to several connectivity problems.

Information and Communications Technologies (ICTs) is the hardware and software that enables data to be digitally processed, stored and communicated. However, this result is not totally surprising, but considering the fact that previous studies conducted by Ongori and Mburu (2010) pointed out challenges affecting the integration of ICT into Nigerian education to include; lack of ICT facilities, low internet connectivity, irregular power supply, and network failure among others. ICTs can be used to access, process, manage and present information. In addition, ICTs could be used for model and control events, construct new understanding and communicate with others. ICT, an interdisciplinary domain, focuses on providing students with the tools to transform their learning and to enrich their learning environment. The knowledge, skills and behaviors identified for this domain enable students to develop new thinking and learning skills that produce creative and innovative insights, develop more productive ways of working 
and solving problems individually and collaboratively. Mbuyisa and Leonard (2015). This means that ICT is a basic necessity in the $21 \mathrm{st}$ century of technology era to achieve results and promote efficiency in education. This suggests that ICT is mostly needed in all aspects to solve problems and to promote growth; hence there should be much budgetary allocation for its deployment in order to satisfy the needs of students in their teaching and learning in the University of Health and Allied Sciences, Ho. Moreover, it can be observed that during the era of COVID-19 pandemic, most institutions switch to the adoption of electronic learning platforms to teach, give assignments and examine students by the use of virtual learning platforms and this needs a good, efficient and reliable internet connectivity to carry out this task. In other words, the satisfactory needs of students is very important therefore management should take appropriate measures to meet the demands of the students feedback in areas seen to be worrisome to them and address them appropriately.

\section{Table 1.4}

Level of satisfaction with health service delivery at UHAS by students

\begin{tabular}{|c|c|}
\hline Statement & \begin{tabular}{|l|l|l|}
1 & $\%$ & 2 \\
$(\mathrm{~F})$ & $(\mathrm{F})$ & \\
\end{tabular} \\
\hline Availability of health service providers (docto & 17 \begin{tabular}{lllll|l}
11.3 & 52 & 34.4 & 82 & 54.3
\end{tabular} \\
\hline Time spent waiting to see a health service provider & \begin{tabular}{llll|l|l}
149.3 & 49 & 32.4 & 88 & 58.3
\end{tabular} \\
\hline Drugs dispensation & 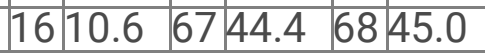 \\
\hline Opening hours & \begin{tabular}{l|l|l|l|l|l}
19 & 12.6 & 82 & 54.3 & 50 & 33.1 \\
\end{tabular} \\
\hline Educational programmes & 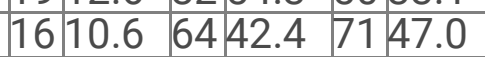 \\
\hline Emergency service(s) & \begin{tabular}{l|l|l|l|l|l|l|}
19 & 12.6 & 59 & 39.1 & 73 & 48.3 \\
18
\end{tabular} \\
\hline
\end{tabular}

Source: Field work (2020)

Research question three. To what extent are students' satisfied with health service delivery at UHAS? The results presented in Table 1.4 shows the responses based on $1=$ Very Satisfied; $2=$ Satisfied; $3=$ Dissatisfied

Table 1.4 illustrates the extent of students' satisfaction with health service delivery in the University of Health and Allied Sciences; Ho. Marginal satisfaction was obtained as a percentage response on the statements depicting drugs dispensation (44.4\%); opening hours (54.3\%) and attitude of staff (53.64\%). Also, statements 1, 2, 5 and 6 with their percentages as follows: availability of health service providers (doctors, nurses) (54.3\%), time spent waiting to see a health provider (58.3\%), educational programmes $(47.0 \%)$ and emergency services (48.3\%) respectively. Statement 1, 2, 5 and 6 show dissatisfaction as the highest percentage responses respectively on health service delivery. It could be observed that majority of the response shows dissatisfaction. Therefore, it can be inferred that the extent of students' satisfaction with health service delivery in the University of Health and Allied Sciences, Ho, was inadequate hence needs a massive improvement in health service delivery on campus. Satisfaction is said to be a state of pleasure or contentment with an action, event or service, especially one that was previously desired and when applied to medical care; patient satisfaction can be considered in the context of patient's appraisal of their desires and expectations of health care, Ofili and Ofovwe (2005). Satisfaction with healthcare services is associated with many contributing factors, among which are related to health providers and healthcare delivery process. Since quality clinical outcome is dependent on patients' satisfaction the latter has come to be seen as a legitimate health care goal and therefore of quality care. Care cannot be of high quality unless the patient is satisfied. 
Nabbuye-Sekandi et al. (2011), define patients satisfaction as a subjective evaluation of the service received against the individual's expectations. Patients' judgment of hospital service quality and their feedback are essential in quality of care monitoring and improvement. Patient satisfaction is measured over a wide range of health service dimensions, including availability, accessibility and convenience of services, technical competence of the providers, interpersonal skills and the physical environment where services are delivered. Patient perceptions of quality are often influenced by their interaction with the health provider. Patient's satisfaction assessment is widely used to evaluate the quality and the effectiveness of various healthcare service deliveries. Patients' satisfaction is a key criterion by which the quality of health care services is evaluated. However, the findings are in contrast to Abbasi et al (2011), whose research showed that students were dissatisfied with medical services, hence there should be an improvement in quality delivery of health services to students on campus and management of UHAS should ensure adequate funds are allocated to provide the necessary basic logistics to enhance quality health care delivery at UHAS. Amidst the COVID-19 pandemic, there is a need to carry out massive educational programmes in order to educate the people in and around the university enclaves about the preventive measures or etiquettes to adopt in other to bring to an end the deadly virus for it not to further spread across. Therefore, management should enforce educational programmes and seminars to create awareness among students about their health services on campus.

\section{Table 1.5}

Level of satisfaction with transport service delivery at UHAS by students

\begin{tabular}{|c|c|c|c|}
\hline Statement & \begin{tabular}{|l|l|l}
1 & 2 & 2 \\
$(\mathrm{~F})$ & $(\mathrm{F})$
\end{tabular} & $\begin{array}{l}3 \\
(F)\end{array}$ & $\%$ \\
\hline Availability of number of buses for students & 117.374 .6 & & 388.1 \\
\hline Efficiency of bus services & 117.3117 .3 & & 985.4 \\
\hline Level of comfort in the buses & 117.374 .6 & & 388.1 \\
\hline Bus loading duration & \begin{tabular}{|l|l|l|}
127.9 & 24 & 15.9 \\
\end{tabular} & & 576.2 \\
\hline Road Network & \begin{tabular}{|l|l|l|l|}
9 & 6.0 & 106.6
\end{tabular} & & 287.4 \\
\hline Fare charges & 159.95133 .8 & 385 & 56.3 \\
\hline Behavior of transport officer(s & 11 & & 84 \\
\hline
\end{tabular}

Source: Field work (2020)

Research question four. To what extent are students' satisfied with transport service delivery at UHAS? The results presented in Table 1.5 shows the responses based on $1=$ Very Satisfied; $2=$ Satisfied; $3=$ Dissatisfied

Table 1.5 indicates the extent of students' satisfaction with transport service delivery at UHAS, Ho, in the study. Two out of seven statements; 5 and 6 showed a marginal satisfaction with little above average percentages that is; fare charges (33.8\%) and behavior of transport officers (drivers, conductors) (33.8\%) respectively. Statements $1,2,3,4$ and 5 showed the highest percentage response of dissatisfaction that can be seen from the data respectively. The results also showed that students were more than half of the total percent were dissatisfied with two statements being fare charges and behavior of transport officers (33.8\%) respectively. Since majority of the statements are seen to have the highest percentage of response as dissatisfied, it can be concluded that the extent of students' satisfaction with transport service delivery at UHAS was poor and needs to be addressed by management of the University. According to Cole, Burke, Leslie, Donald, and Owen (2010) active transport bridges many shared concerns in the public health and transport sectors. To positively affect opportunities for active transport, public 
health and transport professionals are engaging with other sectors, including urban planning, housing, recreation, retail, education, and employer groups. A first step in such inter-sectorial collaboration is to understand the perceptions of key players in all of these sectors. The management of the University should put in place the necessary measures by soliciting funds either from internally generated funds (IGF) with the support from the government for the provision of adequate means of transport for students and also good roads for smooth and comfortable service delivery at UHAS. According to Abbasi et al (2011), whose research showed that students were dissatisfied with transport services. Management has it as a great responsibility to ensure the safety of students on campus with regards to their transportation issues in order not to endanger their lives. Roads should be improved to make movement from one place to another for lectures more comfortable enjoyable. Also, private transports should be allowed in and out of the university to operate to meet the high demand of students needs in terms of transport service delivery at UHAS.

\section{Table 1.6}

Level of satisfaction with hostel service delivery at UHAS by students

\begin{tabular}{|l|l|l|l|l|l|l|}
\hline Statement & $\mathbf{1}$ & $\%$ & $\mathbf{2}$ & $\%$ & $\mathbf{3}$ & $\%$ \\
& $(\mathbf{F})$ & & $(\mathbf{F})$ & & $(\mathbf{F})$ & \\
\hline Availability of rooms & 32 & 21.2 & 63 & 41.7 & 56 & 37.1 \\
\hline Condition of rooms & 29 & 19.2 & 62 & 41.1 & 60 & 39.7 \\
\hline Sanitary facilities (toilets, washrooms, etc. $)$ & 26 & 17.2 & 59 & 39.1 & 66 & 43.7 \\
\hline Water facilities & 23 & 15.3 & 63 & 41.7 & 65 & 43.0 \\
\hline Cleanliness of the environment & 21 & 13.9 & 92 & 60.9 & 38 & 25.2 \\
\hline Lighting facilities & 33 & 21.9 & 84 & 55.6 & 34 & 22.5 \\
\hline Courtesy of hostel staff & 22 & 14.6 & 95 & 62.9 & 34 & 22.5 \\
\hline
\end{tabular}

Source: Field work (2020)

Research Question five. To what extent are students' satisfied with hostel service delivery at UHAS? The results presented in Table 1.6 shows the response based on $1=$ Very Satisfied;

2 = Satisfied; 3 = Dissatisfied

In Table 1.6, it shows that, in terms of hostel service delivery, the students were somehow satisfied with availability of rooms (41.7\%), condition of rooms (41.1\%), cleanliness of environment (60.9\%), lighting facilities (55.6\%) and courtesy of hostel staff (62.9\%). On the other hand, the students were dissatisfied with sanitary facilities (such as; toilets, washrooms) (43.7\%) and water facilities (43.0\%). Although a few students were very satisfied with hostel services but were far below the desirable rate of satisfaction per the data received. This suggests that adequate measures should be taken by management of the University to address these challenges respectively in areas identified by the students. Thus, it could be said that the students at UHAS were somehow satisfied with hostel service delivery at the University of Health and Allied Sciences, Ho, even though the University adopted outsourcing system of hostel services to satisfy the needs of students' accommodation on campus. This can be explained by the fact that congestion has been a common feature in most Ghanaian universities, which has led to overstretching of facilities. For instance, a room meant to be occupied by four students is occupied by about eight or more students since there are always limited spaces. This result supports the observation of Alani, Okunola, and Subair (2010) who deduced that the conditions of the hostels were very pathetic, with most hostels being jam-packed with more students than the required number. The authors further noted that some 
hostels lack basic facilities like adequate water and sanitary facilities. The conditions as observed by these authors' could have accounted for demonstrations or outright riot by students.

According to Khozaei, Ramayah, Hassan, and Surienty (2012) the availability of students housing has been acknowledged as one of the major issues that students must consider when choosing a University. If universities are unable to provide quality and affordable housing for students, students face additional pressure, and the lack of affordable off-campus housing may become a significant problem. The result is that, in choosing between two similar universities, students may prioritize their accommodation before considering enrolment.

Implications for Management

The finding of this study shows that students were dissatisfied with health and transport service delivery in the University of Health and Allied Sciences, Ho. The findings also indicated that students were somehow satisfied with library, hostel and ICT services delivery. This outcome will help management of the University to target these areas by providing more resources in order to bring improvement so as to make students experience conducive environment for the attainment of necessary skills and academic abilities as possible. The outcome of this research has serious implications for educational management. This is so because, by giving students opportunity to express their opinions and views on services provided, the management of the university would be aware of the feelings and educational experiences of students. Such awareness will enable management meet the expectations of students and the information provided could be used to bring improvements in service delivery. The study has also brought to light the various indicators that will contribute to the reputation of the University of Health and Allied Sciences, Ho, in the Volta Region of Ghana, which, if adopted, could further place the institution at a competitive edge with other institutions of higher learning in the world.

It is also generally observed that educational institutions in Ghana have not incorporated satisfaction measurement into its quality processes. Hence there is a need to give due attention by introducing feedback channels through which students' satisfaction surveys could be used to effect continuous improvements into the quality of service delivery needs of the students in order to achieve their academic and social goals. It is therefore imperative that the university management should endeavor to maximize students' satisfaction and minimize dissatisfaction to its minimum level with service delivery. Also, management should know the areas of deficiency in order to rectify and add value to their services, so as to retain students as well as improve institutional performance.

\section{Conclusion}

This study assessed university students' satisfaction in five areas of service delivery in the University of Health and Allied Sciences, Ho in the Volta Region of Ghana. Based on the data analysis and presentation, it was concluded that the university students were dissatisfied with health and transport services delivery, whereas they were somehow satisfied with library, ICT and hostel services delivery.

The findings also confirmed that service delivery varied with institutional type in terms of health and library services while they did not differ in terms of transport, hostel and ICT services. 
Majority of the students at UHAS were not satisfied with service delivery in the areas identified, therefore management should endeavor to put in place the necessary measures needed as feedback from students to meet the urgent demands in order to satisfied them holistically.

\section{Recommendations}

\section{The recommendations offered are that:}

1. Based on the findings, the University management should enhance students' satisfaction by ensuring all services that contribute to academic and social life of students in the University of Health and Allied Sciences, Ho, are delivered to acceptable and satisfactory standards.

2. The Management of the University should ensure adequate provision of ICT services, considering the importance of e-learning opportunities (such as; distance learning and visual learning amid COVID-19 pandemic) in the present day of 21 st century. If implemented, will go a long way and will place Ghanaian students at par globally with others.

3. Government should provide the necessary financial support or resources to management of the University to meet acceptable standards in service delivery.

4. The Management of the University should strongly collaborate with educational stakeholders in and outside the university enclaves together with philanthropist to help internally to generate funds to support the quality service delivery to students.

5. Surveys to assess students' satisfaction with university service delivery should be carried out on regular basis by management of UHAS to ascertain the satisfaction needs of students.

\section{Declarations}

Competing interests: The author declare no competing interests.

\section{References}

Abbasi, M. N., Malik, A., Chaudhry, I. S., \& Imdadullah, M. J. A. S. S. (2011). A study on student satisfaction in Pakistani universities: The case of Bahauddin Zakariya University, Pakistan. Asian Social Science, 7(7), 209.

Alani, R. A., Okunola, P. O., \& Subair, S. O. (2010). Situation Analysis of Students' Welfare Services in Universities in South-Western Nigeria: Implications for Students' Personnel Management Practice. Online Submission, 7(10), 42-50.

Ayodele, A. S., \& Falokun, G. O. (2003). The Nigerian economy: Structure and pattern of development. JODAD. 
Cole, R., Burke, M., Leslie, E., Donald, M., \& Owen, N. (2010). Perceptions of representatives of public, private, and community sector institutions of the barriers and enablers for physically active transport. Transport policy, 17(6), 496-504.

Dei Ofori-Attah, K. (2007). Urbanization and schooling in Africa: Trends, issues, and challenges from Ghana during the colonial era. In International Handbook of Urban Education (pp. 23-48). Springer, Dordrecht.

Ekpoh, u. I. (2018). Assessing university students'satisfaction with service delivery: implications for educational management. Sciences, 6(6), 48-60.

Gyamfi, D. A., Agyeman, A., \& Otoo, B. K. (2012). Assessing the provision of quality students' service and satisfaction in tertiary institution in Ghana: Using Cape Coast Polytechnic as Case Study. Asian Journal of Business and Management Sciences, 1(12), 20-32.

Hussain, N., \& Bhamani, S. (2012). Development of the student university satisfaction scale: Reliability and validity. Interdisciplinary Journal of Contemporary Research in Business, 4(3), 332-341.

Katamei, J. M., \& Kiprop, C. (2015). Student perception on service delivery at Moi University: a case study of Privately Sponsored Student Programme (PSSP) in Eldoret west campus, Kenya. International Journal of Education and Research, 3 (5), 49, 64.

Khozaei, F., Ramayah, T., Hassan, A. S., \& Surienty, L. (2012). Sense of attachment to place and fulfilled preferences, the mediating role of housing satisfaction. Property Management.

Mast, F. W., \& Zaltman, G. (2005). A behavioral window on the mind of the market: An application of the response time paradigm. Brain Research Bulletin, 67(5), 422-427.

Mbuyisa, B., \& Leonard, A. (2015). ICT adoption in SMEs for the alleviation of poverty. Paper presented at the International Association for Management of Technology, IAMOT 2015 Conference Proceedings.

Mu, C. (2007). Marketing academic library resources and information services to international students from Asia. Reference Services Review.

Nabbuye-Sekandi, J., Makumbi, F. E., Tugumisirize, J., Nshimye, E.,et al. (2011). Patient satisfaction with services in outpatient clinics at Mulago hospital, Uganda. International Journal for Quality in Health Care, 23(5), 516-523.

Nnadozie, A. C. (2006). Collection development activities in selected academic Libraries in Nigeria. Nigerbiblios vol 17 (1-2).

Ofovwe, C. E., \& Ofili, A. N. (2005). Indices of patient satisfaction in an African population. Public health, 119(7), 582-586. 
Ongori, H., \& Mburu, P. T. (2010). Usage of information communication technologies (ICTs) in information seeking amongst university students in Botswana. E3 Journal of Business Management and Economics, 1(1), 18-25. 